\section{Regards sur l'économie allemande}

Bulletin économique du CIRAC

$91 \mid 2009$

Varia

\title{
Face à la crise, une Allemagne confiante en elle- même
}

René Lasserre

\section{(2) OpenEdition}

1 Journals

Édition électronique

URL : http://journals.openedition.org/rea/3663

DOI : 10.4000/rea.3663

ISBN : 978-2-8218-0878-2

ISSN : 1965-0787

\section{Éditeur}

CIRAC

Édition imprimée

Date de publication : 1 mai 2009

Pagination : 1-2

ISSN : 1156-8992

\section{Référence électronique}

René Lasserre, "Face à la crise, une Allemagne confiante en elle-même », Regards sur l'économie allemande [En ligne], 91 | mai 2009, mis en ligne le 20 mai 2009, consulté le 22 septembre 2020. URL http://journals.openedition.org/rea/3663 ; DOI : https://doi.org/10.4000/rea.3663 


\section{Face à la crise, une Allemagne confiante en elle-même}

Depuis le début de l'année, les craintes d'un choc majeur pour l'économie allemande n'ont fait que se confirmer. De semaine en semaine, la chute de l'activité n'a fait que s'amplifier, et désormais les prévisions concordent: avec un recul de PIB de l'ordre de $6 \%$ en 2009, la République fédérale se trouve bel et bien confrontée à la plus profonde récession de son histoire.

De par sa spécialisation, elle subit, plus sévèrement que tout autre, la rétraction de la demande mondiale en biens d'investissements et en bien durables. Ses marchés à l'exportation se sont effondrés de $20 \%$, entraînant un recul brutal de la production industrielle qui devrait encore se prolonger dans les prochains mois, même s'il amorce un léger ralentissement. La montée du chômage partiel, avec plus de 670000 salariés en avril, témoigne de la rudesse du choc et préfigure une recrudescence du chômage qui pourrait refranchir la barre des 4 millions à l'automne et celle des 5 millions à la fin 2010. Quant à la consolidation des comptes publics, si chèrement acquise depuis 2007, elle semble largement compromise : sous le double effet des plans de relance et de la récession, le déficit public devrait atteindre le taux record de 5,5\% du PIB en 2010, effaçant les $4 \%$ de 2003.

L'Allemagne se voit à nouveau confrontée à l'ambivalence d'un modèle de production et d'insertion dans l'économie globale qui la rend fortement vulnérable aux chocs externes et l'expose à des ajustements périodiques répétés. Sans que l'on puisse encore en mesurer l'ampleur et la durée, ceux-ci s'annoncent, une fois encore, comme une épreuve au plan social. Pourtant le pays fait front dans la tourmente, et à quelques mois d'une échéance politique majeure, les acteurs socio-économiques, les décideurs politiques et l'opinion font preuve d'un remarquable sang froid dans un débat public qui reste étonnamment ouvert et constructif.

Alors qu'ils fêtent le $60^{\mathrm{e}}$ anniversaire de la création de l'Etat dans lequel ils ont pu construire la démocratie et finalement se réunir, les Allemands abordent en fait cette crise d'ampleur exceptionnelle dans un état d'esprit inédit : pour la première fois, ils répondent ensemble à un défi purement externe, celui de la crise provoquée par la dérive des marchés financiers américains. Et ils le font après avoir réussi à surmonter une crise d'une toute autre nature et d'une toute autre ampleur, la crise interne commune héritée de l'unification et de l'adaptation conjointe des deux sociétés à l'intégration européenne et à la globalisation. Crise tardive qui ne s'est révélée qu'à la veille du nouveau millénaire, après une décennie de co-existence, lorsqu'il a enfin fallu adapter la difficile gestion de la maison commune dans un environnement entre temps profondément transformé.

Cette crise d'adaptation a été celle de "la troisième unité ", non pas de celle des traités initiaux de l'union monétaire et de l'union politique, mais bien celle de "l'unité de gestion domestique ", avec la nécessaire 
mise à plat des solidarités et de la répartition des charges. Elle a demandé trois législatures dont il aura fallu que la dernière soit, comme dans les années soixante, à la fin du "miracle ", une législature de Grande coalition. C'est elle qui a scellé l'union sociale avec l'alignement, à bien des égards symbolique, de l'allocation chômage (ALG II - HartzIV) des nouveaux Länder sur celle de l'ouest au $1^{\text {er }}$ juilllet 2006 puis, plus déterminante encore, l'incontournable consolidation budgétaire de l'Allemagne unie avec la hausse de la TVA de 3 points au $1^{\text {er }}$ janvier 2007.

$\mathrm{Au}$ regard du chemin parcouru, de cette épreuve difficile mais finalement réussie, la résorption de la crise bancaire internationale, qui permettra demain le retour à la confiance et le redémarrage de l'économie réelle, n'apparaît aujourd'hui en Allemagne qu'un préalable technique à la sortie de crise. Pour le reste, les ajustements budgétaires et sociaux internes, tout comme la réforme du marché du travail et la valorisation des ressources de main-d'œuvre (voir infra E. Spitznagel) qui ont permis à l'économie allemande de restaurer sa compétitivité internationale et de renouer avec la croissance dès 2006, ont déjà été réalisés.

Mais par delà cette évocation rapide du redressement exemplaire que l'Allemagne a opéré au cours des six ou sept dernières années, les contributions des éminents auteurs que nous avons réunis dans ce dossier spécial consacré au $60^{\mathrm{e}}$ anniversaire de la création de la République fédérale nous indiquent, chacune à sa manière et avec l'empathie qui convient en pareille circonstance, bien d'autres dimensions sur lesquelles l'Allemagne a toutes raisons de fonder sa confiance en l'avenir.

Cette démocratie modeste et exigeante, resurgie des ruines d'un cataclysme politique et moral sans précédent, a su se construire une légitimité qui lui a permis de s'assurer la reconnaissance internationale, de réaliser l'unité des Allemands et d'assumer pleinement ses responsabilités européennes. Elle s'est donnée d'entrée, avant même d'avoir atteint sa propre vitesse de croisière, un système de régulation économique et sociale désigné sous le terme d' "économie sociale de marché" qui, en parvenant à concilier l'impératif de l'efficacité économique et de l'équité sociale, a fait la preuve de son adaptabilité aux mutations de l'économie internationale et de sa capacité presque intacte à promouvoir de nouvelles règles du jeu économique en période de crise. Dans le domaine économique encore, mais cette fois au plan monétaire, l'apport de la République fédérale n'a pas non plus été mince : elle a non seulement patiemment enseigné les vertus de la stabilité monétaire aux Européens, mais en s'appuyant sur l'expérience du Deutsche Mark et sur les circonstances, elle a donné une monnaie solide à l'Europe. Enfin, le plus beau cadeau que les Allemands ont fait à l'Europe, c'est peut être d'avoir renoncé à être "spécifiquement allemands " et de s'être en quelque sorte normalisés, bref d'être devenus des Européens comme les autres, d'avoir pleinement retrouvé confiance en eux-mêmes. Ce qui tendrait à expliquer que forts de leur expérience et des épreuves qu'ils ont traversées, ils témoignent d'une aptitude au changement qui leur permet d'aborder désormais plus sereinement les mutations de la société globale.

René Lasserre, le 10 mai 2009 